\title{
Investigation and optimization for the dynamical behaviour of the vehicle structure
}

\section{Omid Zargar, Abolfazl Masoumi* and Amir Ostadi Moghaddam}

\author{
School of Mechanical Engineering, College of Engineering, \\ University of Tehran, Tehran, Iran \\ *Email: amasomi@ut.ac.ir \\ Phone: +989123841995; Fax: +982188013029
}

\begin{abstract}
Conceptual modelling is known as a well suited alternative approach for Computer-Aided Engineering (CAE) analysis in automotive industry. In this paper, an improved conceptual modelling method in which beams and panels of the structure are modelled as simplified beam elements has been proposed. To explore the advantage of conceptual modeling in determining the resonant frequencies/mode-shapes, a case study for wheelhouse was performed. Firstly, an experimental test and advanced CAE analysis were carried out to measure the wheelhouse dynamic characteristics. The advanced CAE model was then validated by means of Modal Assurance Criterion and natural frequencies by associated experimental measurements. The results of wheelhouse concept model compared to the advanced CAE and experimental model in low frequency range, showed that the error percent of natural frequency is lower than $10 \%$ and the Modal Assurance Criterion is above 0.75 for the first four mode shapes of wheelhouse structure. Finally, the conceptual model is used as a baseline for optimization. The genetic algorithm was implemented to maximize the first natural frequency to $41.74 \mathrm{~Hz}$. So The genetic algorithm successfully provided new possibility for optimization by attempting to influence the first mode shape by means of the cross section characteristics. Due to the accuracy and reliability of developed conceptual model, this modelling approach can be a crucial tool in CAE and vibration analysis of vehicle in the early design phase. The proposed method allows the designer to give the results of design changes very quickly by neglecting details. Therefore, for the analysis of the vehicle performance in NVH domain, the proposed method could be considered in the conceptual design phase.
\end{abstract}

Keywords: Conceptual model; vehicle structure; advanced CAE model; optimization; genetic algorithm.

\section{INTRODUCTION}

In general, finite element modelling of vehicle parts is classified into two different techniques. In the first method, which is termed as advanced CAE model, the detailed geometry of all components are considered, while in the second approach (conceptual modelling) only basic frames and initial dimensions are taken into consideration. Due to fast performance computations need of industry, the conceptual modelling method is still an attractive research area for the automotive CAE investigations[1-4]. Recently, considerable studies have been devoted to this subject, which is motivated greatly by its advantages in vehicle parts modeling [5-7]. Fard [8] developed a concept model for the 
body-in-white structure in accordance with its corresponding physical properties of its structural members and found a close agreement between concept model results and test data. [9] improved Fard's method by changing the 1-D elements to some optimal cross sections in concept model to reduce the vehicle weight. Moroncini et al. [10] considered concept modelling with beam and shell elements together for optimization of the sheet thickness to achieve an appropriate level of Noise, Vibration and Harshness (NVH) and reduce the body weight of BMW. Gur and Wagner [11] Conducted an experimental study to develop correlated CAE models for lightweight vehicle design with the use of carbon fiber composite vehicle body parts to determine the material and $\mathrm{NVH}$ characteristics of the carbon fiber composite materials. Lee et al.[12] investigated the effects of joints stiffness in vehicle vibration and presented a method for correcting a rod model. They introduced correct coefficients for the rod model using surface answer method to reduce its stiffness approximation to the real model. Long [13] proposed a method related to the performance targets of new vehicle with a group of design parameters (joints). This method consists of two steps. In the first step, the stiffness and mass of an automotive joint is specified. Then, the most efficient, feasible design for which characteristics are close to given performance targets is found. Kiani et al. [14] presented an approach for the structural performance evaluation of a vehicle model by means of the joint stiffness. They showed that the car body structure evaluation based on the optimum joint stiffness has much better performance relative than the baseline model without a weight penalty. Maressa et al. [15] proposed an innovative procedure based on the wave-based sub structuring (WBS) technology to achieve a database framework for joint concepts. They analyzed an industrial case study by using the proposed methodology which was validated through static and dynamic Finite Element (FE) simulation. Mesh morphing [16] is another method applied for developing new models. In this approach the evaluation of design concepts starts from the morphed predecessor models and validated solutions can be incorporated in the first version of the CAD model. Mundo et al. [17] and [18] suggested conceptual modelling using equal elements and the main model joints. In their model, an equal standard cross section is defined for calculating the cross section properties of equal beam elements. For the evaluation of panel's effects in the body, they studied the use of 2-D parts with coarse mesh using mesh morphing technique. Tebby et al. [19] and [20] developed a method in which vehicle structure is represented by using beam elements. Their method uses a numerical finite element method and is able to determine unknown deflections and reaction forces as well as the internal loading on each member. Their method also was used to conduct a parametric optimization for torsion stiffness. Zhu et al. [21] considered the vehicle front rail using robust optimization for vehicle weight minimization. In their study surface answer method was coupled with experimental design method. Shin et al. [22] used topology optimization to maximize the stiffness of A-pillar of the low speed vehicle body. They determined the thicknesses of the cross-sections to minimize the mass of the body while design specifications were satisfied, too. Marburg and Hardtke [23] presented design optimization of the geometry of a vehicle hat-shelf for the vehicle interior noise reduction. These noises were due to three different excitations for two cases of fluid damping. Liu and Vagner [24] and [25] proposed a vibration isolation seating system for passenger/light-duty vehicles to improve ride quality. They presented mathematical models to describe the vehicle's passive suspension and seating systems, the occupant's response to vertical motions, and two force actuators. Gundogdu [26] and [27] presented an optimization of a four-degrees-offreedom quarter car seat and suspension system using genetic algorithms to determine a set of parameters to achieve the best performance of the driver. Hassen et al. [28] 
Investigated the dynamic behavior of a quarter car vehicle system using the Operational Modal Analysis (OMA) using Independent Component Analysis (ICA). Quanbo and Wei [29] simulated crashworthiness process and its effect on front rail in sedans. In this study, the values of energy absorption were compared before and after crash. Angelo et al. [30] have reported the influence of front wheelhouse elements of vehicle quarter model on its aerodynamics performance. In fact, they conducted this study for identifying the aerodynamic loads which were generated by these components and consequent effects on the surrounding flow dynamics of wheel with computer simulations. Lee and Thompson [31] analyzed properties of frequency response with a calculated model for a vehicle system consisting of wheels, suspension system and vehicle body. Vehicle physical parts are equalized by substructures used for the vehicle parts physical properties. Hurlebaus et al. [32] used experimental modal analysis for PVDF films with sensors and actuators. They implemented the modal controller on a digital controller board. They also carried out experimental tests with the floor panel and center panel of a car body to validate the proposed concept. Sun, Chen and Zhao [33] performed modal analysis in order to obtain the modal frequency of actual structure of a car body-in-white, find the weak positions of the body design and improve the dynamic performances. Fard et al. [34] provided important knowledge to predict the structural resonant frequencies and corresponding vibration mode shapes of the vehicle seat coupled with occupant from the seat alone or seat bare-frame (seat without foam cushion). Zou et al. [35] Simplified the seats to a cantilever beam physical model. Moreover, seat modal test method is proposed to model seat vibration characteristics and it validated by the mode theory. Muller et al. [36] performed static and dynamic analyses for motor loads. They optimized motor comportment rubber spring with finite element and presented active vibration absorption for motor comportment noise reduction.

In this study, a new improved conceptual model has been presented based on modifications suggested by Mondo et al. [18]. It is then used to analyze wheelhouse dynamics behavior of a sedan as a case study to provide deep insight of such model application. Then the modal experiments and simulation analysis were compared with the results of conceptual model. Finally, it was shown that the first natural frequency can be maximized by application of conceptual model together with optimization with GA. Using conceptual modeling technique, it is possible to calculate vehicle dynamic characteristics such as natural frequencies and mode-shapes accurately by less computational effort in comparison to conventional methods. Moreover, using the proposed method the designer can give the results of design changes very quickly by neglecting details.

\section{METHODS AND MATERIALS}

\section{Design and Experiment Procedure}

Structural resonant frequencies and corresponding mode shapes of vehicle body subassemblies can be determined by means of experimental modal analysis. Quality of main structure behavior against dynamic loads can be evaluated using such analysis. For the extraction of structural resonance and mode shapes of the wheelhouse, fixed shaker test, which is a regular method in modal testing, was used. The used test setup consists of an electromagnetic shaker (B \& K 4808), plastic stringer, charge amplifier (B \& K 2786), 1-axial accelerometers, data logger $\left(\mathrm{B} \& \mathrm{~K} 356^{\circ} \mathrm{C}\right)$, loading transducer $\left(8200^{+} 2647\right)$ and Pulse 12 software. Elastic ropes were used to suspend the wheelhouse structure so as to be nearly free in six axes. Consequently, the modal characteristics of wheelhouse were 
measured in the free-free boundary condition. Adhesive wax was used to mount the accelerometers to the different areas of the wheelhouse structure. In modal test, FRF (Frequency Response Function) diagrams are defined with the shaker input at a fixed point and the sensor output at various points. For obtaining natural frequencies, maximum points in diagrams should be identified. Also shape of modes of any structure is simply extracted from resonance domain of FRF diagrams. For this reason, 37 points of the wheelhouse body were measured. Figure 1 illustrates the test rig which was used for modal measurements.

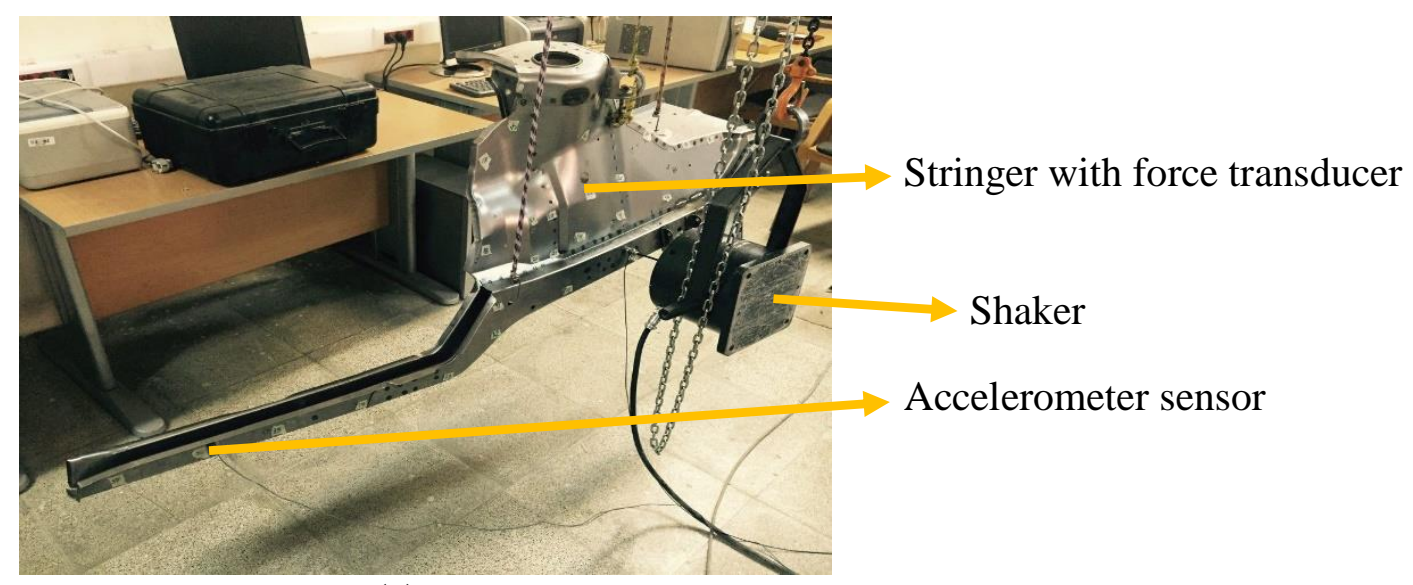

(a)

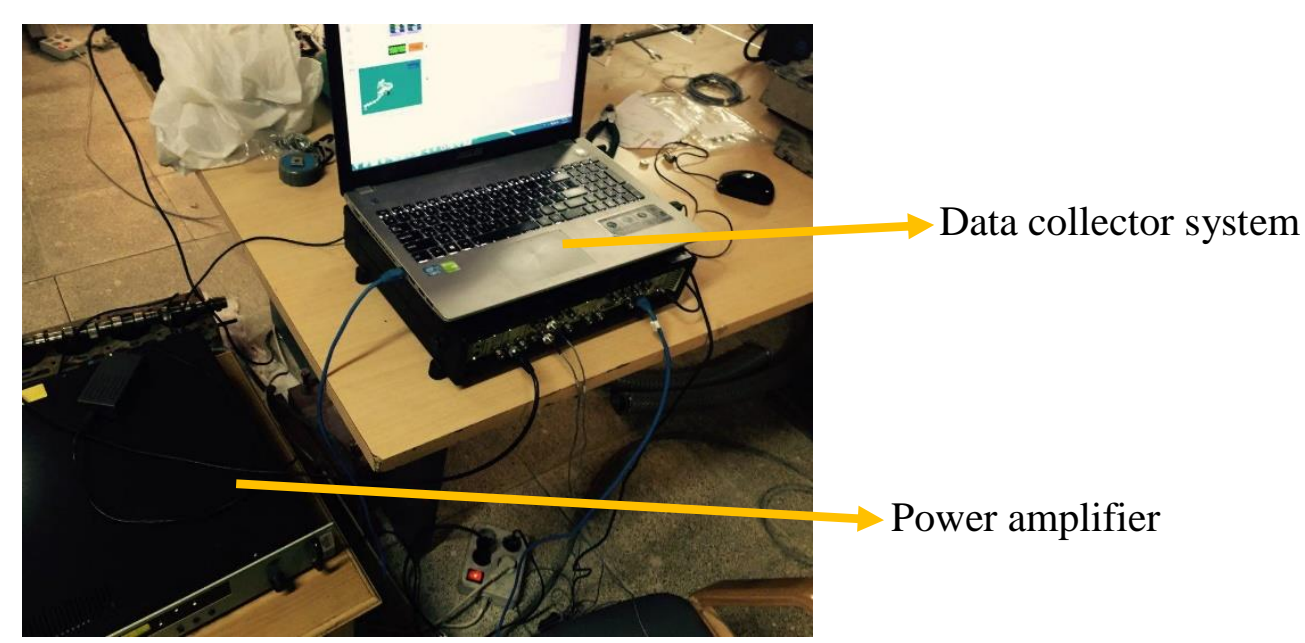

(b)

Figure 1. General view of experimental setup (a) wheelhouse structure assembly; (b) Test data.

\section{Numerical Scheme}

The wheelhouse of a mid-size sedan car was considered as case study. FE methods and CAE techniques were used for analysis. Altair Hyper Works in coupled with MSC Nastran software are used to numerically analyze the wheelhouse dynamic behavior. It should be noted that the wheelhouse body is made of steel with total mass of $10.61 \mathrm{~kg}$. A combination of triad and quad elements (e.g., PSHELL in Nastran software) was used to discretize computational domain (Figure 3). When an FE model is to be validated, the requirement on the convergence of the model must be satisfied. In this study, a grid independent technique is used for FE model to determine the grid convergence. Five 
different elements are applied to the same structure. The natural frequencies between the same modes of these four sets can then be used to determine the convergence. Figure 2 shows the natural frequency differences between the same modes when five different elements are applied in the FE model of the wheelhouse. It can be seen that for these four sets the difference is less than $1.5 \%$ which is an acceptable threshold. The optimum mesh sizes is $8 \mathrm{~mm}$ and the total number of grid elements is 22629 . Subsequently, joint constraints which were spot welded and bead welds (CO2 weld) in this case (e.g., RBE3 and RBE2 in Nastran software [37], respectively), were added to simulate contact region as can be seen in Figure 3. It should be mentioned that in the wheelhouse structure, the total numbers of spot welds and bead welds were 249 and 23, respectively.

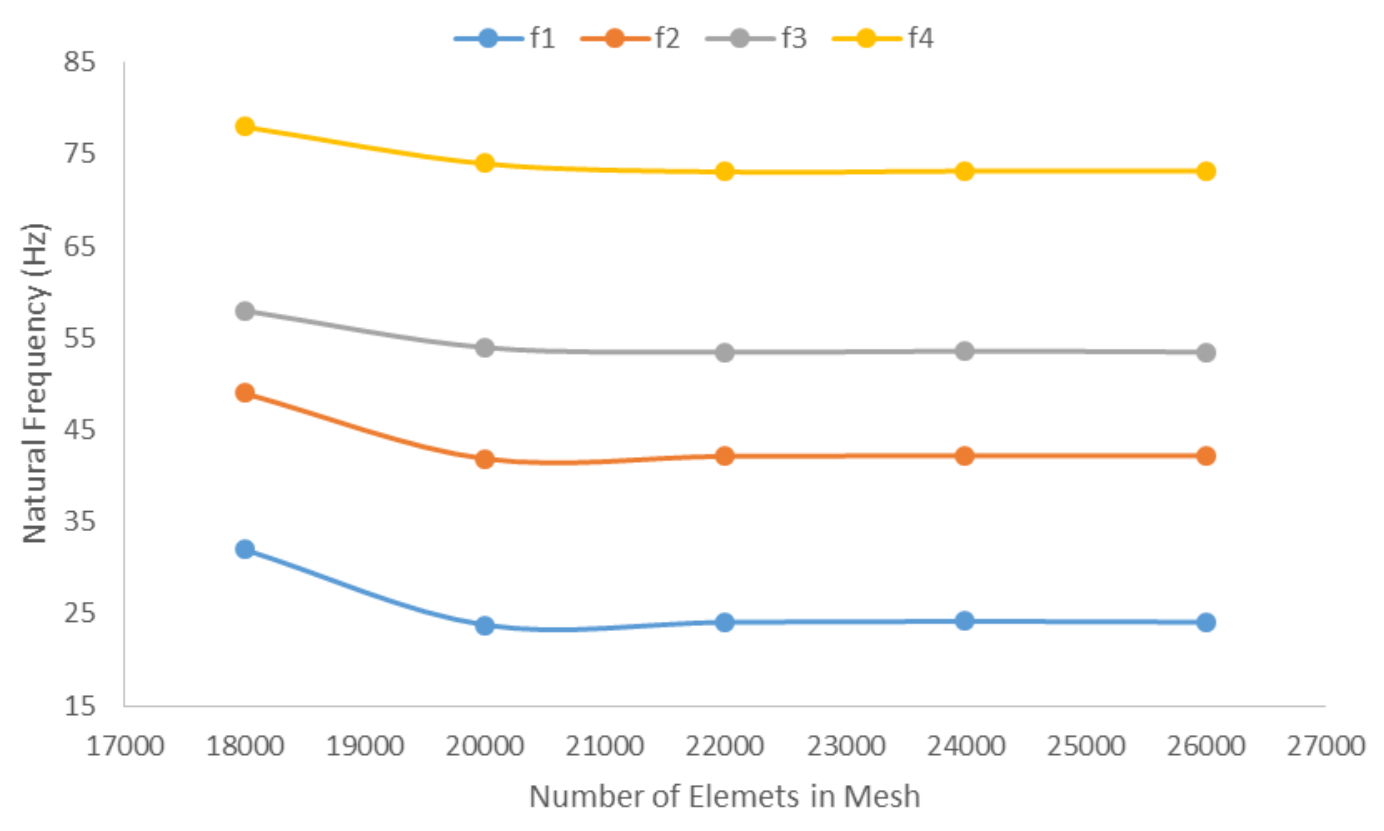

Figure 2. The convergence diagram.

\section{Concept Modeling}

In this section, the vehicle wheelhouse was modelled using FE methods. The wheelhouse model must be validated with its corresponding test data. This model will be used instead of the baseline wheelhouse in the next steps. The developed model was accurate enough to characterize the resonant frequencies and corresponding mode shapes which represent major behaviors of wheelhouse structural. Therefore, a conceptual model, which represents the main characteristics of the system, was developed for the wheelhouse. In this study, the conceptual model for wheelhouse structure was implemented by using 1D elements for beam elements and available panels of structure. The connection between some equivalent panels with their adjacent beam elements was done by rigid elements (e.g., RBE2 in Nastran software). Beam elements (e.g., PBEAM in Nastran software) were used to model the components of the wheelhouse structure. These elements have the same cross section as those corresponding to the beam parts at the wheelhouse while standard cross sections were used for the panels. 


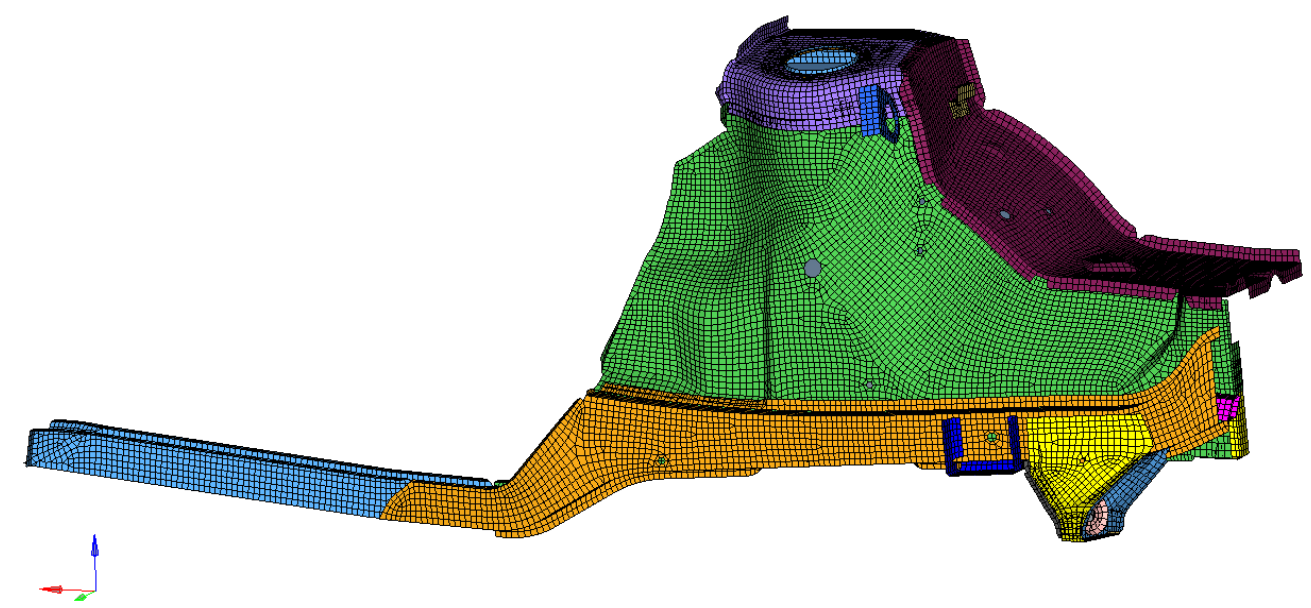

(a)

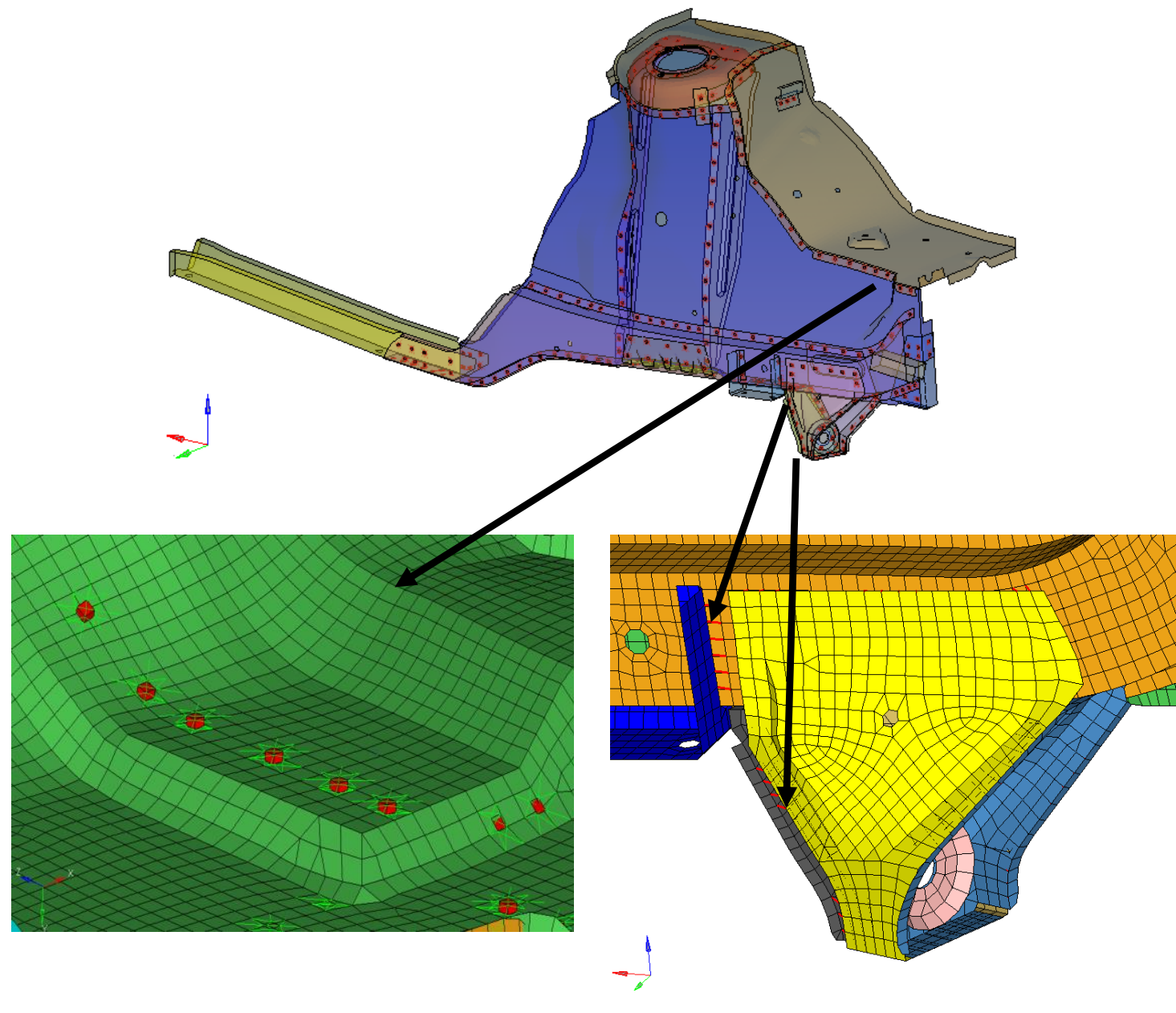

(1)

(2)

(b)

Figure 3. (a) General view of grid mesh. (b) Representation of welds on wheelhouse: (1) spot welds (2) bead welds.

For arbitrary cross sections, effort was made to choose simplified standard cross sections such as box profiles similar to the main section. It should be noted that 1-D element of wheelhouse structure conceptual model, should not merely undergo tension 
and pressure. For example, the front side rail was simplified using beam modelling approximation as seen in Figure 4. It should be noted that in modelling beam parts based on changes made in the length of beam elements cross sections, it is better to define equivalent element for each part. Also the effects of non-uniformity of these parts of the advanced model, such as holes and spot welds, must be considered. The method chosen for these effects was to reduce section lateral thickness. For equivalent panels (Figure 4), firstly, due to high stiffness, their frame was modelled by beams with the simplest cross section, having the same thickness. In the next step, in distortion regions of panels, different beams are used to show high stiffness of these parts. After that, for panels with discontinuity in some parts of their frame, beam elements were used with smaller cross sections to obtain less stiffness as seen in Figure 4. Finally, for equalizing the mass of beam element with panels, the dimensions of box cross sections were adjusted.
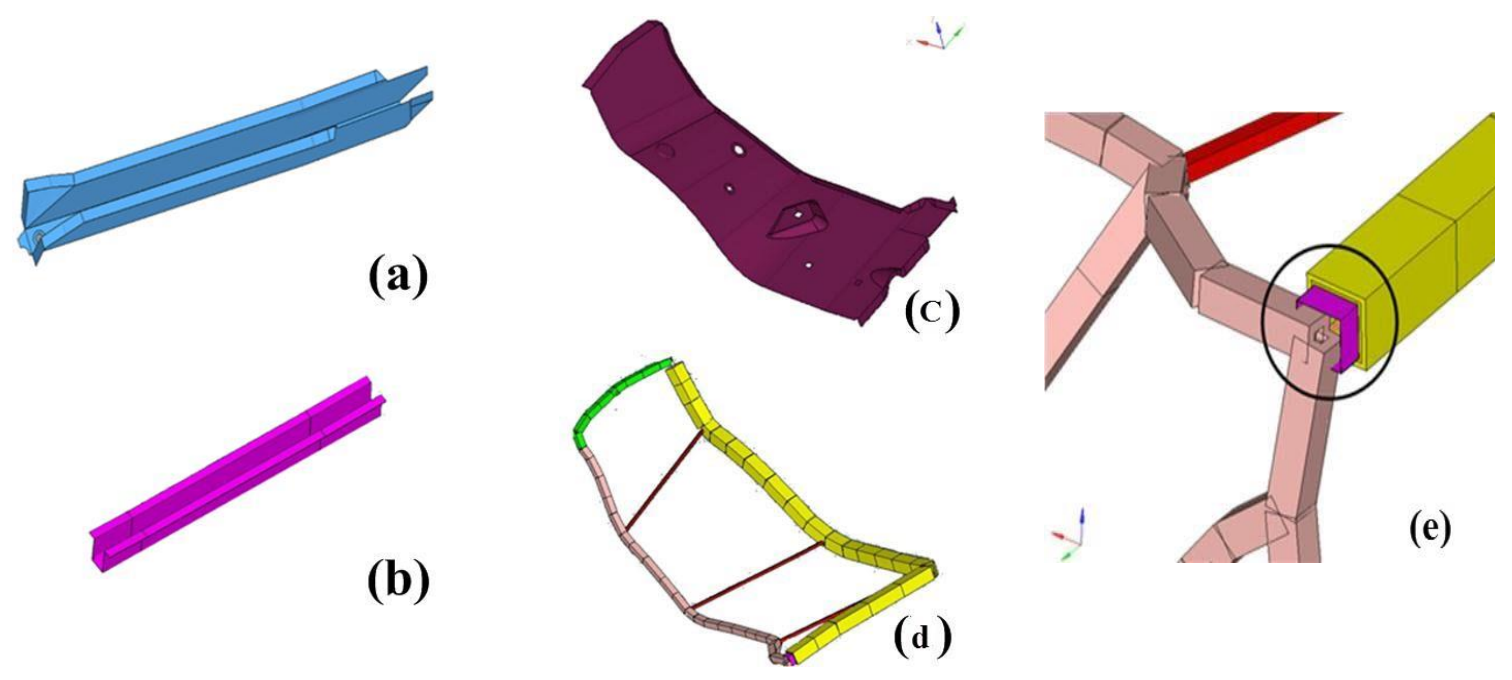

Figure 4. Conceptual modelling of (a) front rail before simplification (b) front rail after simplification (c) one of the main panels before simplification (d) one of the main panels after simplification (e) small beam in frame of panel

\section{Optimization Algorithm}

Traditional optimization methods which use the objective function gradient for domain search may face with some limitations. The limitations of these methods appear when the objective function and the constraints of the optimization problem are discontinuous. GA which was developed by Holland [38] is a powerful computational method which incorporates a successful direct searching algorithm to solve linear and nonlinear optimization problems. Therefore, this method can be used for optimization problems in which the derivatives of the objective function and constraints are not available. When the design vectors are discrete, GA changes the available discrete set towards generating a fitter generation of design points. GA operators include selection, cross over and mutation [39], [40]. Concerning mating, a set of chromosomes is selected in every generation based on their relative fitness. This allows fitters more chance for passing their genes into the next generation. The stochastic universal sampling method [41] has been used in this research for selecting chromosomes for mating based on their fitness values in the current population, Eq. (1): 


$$
P\left(x_{i}\right)=\frac{F\left(x_{i}\right)}{\sum_{i=1}^{N_{\text {ind }}} F\left(x_{i}\right)}, \quad i=1,2, \ldots, N_{\text {ind }}
$$

where $F\left(x_{i}\right)$ and $P\left(x_{i}\right)$ are fitness of chromosome and probability, respectively. $N_{\text {ind }}$ is the number of individuals.

The chromosomes are then selected randomly through cross over for producing offspring. This process continues to have the final generation, where the best fitness is achieved and is considered as the optimum point. Recently, GA is used in some researches. Truong, Nguyen and Kim [42] proposed an effective method for optimizing space steel frames with semi-rigid joints using practical advanced analysis (PAA) and micro-genetic algorithm $(\mu \mathrm{GA})$. The results of steel frame examples prove that the proposed method is computationally efficient. Chang et al. [43] assessed two kinds of multi-chamber plenums within a fixed space. To assess optimal plenums, a genetic algorithm is applied. The results reveal that the maximum value of the transmission loss can be improved at the desired frequencies.

\section{RESULTS AND DISCUSSION}

\section{Modeling, Simulation and Experimental Results}

The final conceptual model of wheelhouse was simplified with 321 1-D equivalent beam element with the properties of standard cross section for beam elements and panels. The information of advanced and conceptual model of the wheelhouse is given in Table 1. Also the final wheelhouse model is given in Figure 5.

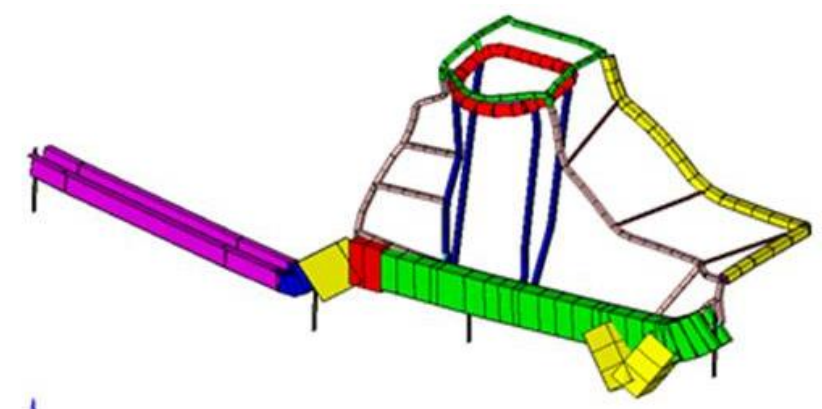

Figure 5. Final conceptual model of wheelhouse structure.

Table 1. Comparison of detailed information for advanced and conceptual model.

\begin{tabular}{lccc}
\hline Advanced model & numbers & Conceptual model & numbers \\
\hline Shell elements & 22629 & Beam elements & 321 \\
Spot welds & 249 & Solid elements & 27 \\
Bead welds & 23 & Concentrated mass & 33 \\
Mass & 10.6 & Mass & 10.7 \\
Time of solution & $1.20 \mathrm{~min}$ & Time of solution & $6 \mathrm{sec}$ \\
\hline
\end{tabular}

Comparison of resonant frequencies values and those of Modal Assurance Criterion (MAC) [44] between the experimental and numerical results have been detailed in Table 2 . Regarding what preceded, error percent $(\Delta \%)$ of natural frequencies and MAC of the advanced and test models are computed to validate the results. Eq. (2), has been 
used for the calculation of MAC index between similar modes of two models. K, $\Phi_{E}$ and $\Phi_{A}$ are mode number, the Matrix of Eigen vectors for the experimental results and advanced model, respectively.

$$
\left.M A C_{E, c}\right|_{k}=\frac{\left(\left\{\Phi_{E}\right\}_{k}^{T}\left\{\Phi_{C}\right\}_{k}\right)^{2}}{\left(\left\{\Phi_{E}\right\}_{k}^{T}\left\{\Phi_{E}\right\}_{k}\left\{\Phi_{C}\right\}_{k}^{T}\left\{\Phi_{C}\right\}_{k}\right.}
$$

Table 2. Comparison of wheelhouse resonant frequencies and MAC.

\begin{tabular}{ccccc}
\hline Mode number & Experiments $(\mathrm{Hz})$ & Simulation $(\mathrm{Hz})$ & Error $(\Delta \%)$ & $\mathrm{MAC}$ \\
\hline 1 & 23.8 & 24 & 0.83 & 0.98 \\
2 & 38.6 & 42.2 & 9.3 & 0.76 \\
3 & 50 & 53.5 & 7.0 & 0.82 \\
4 & 76 & 73.1 & 3.8 & 0.81 \\
\hline
\end{tabular}

The main structure nodes in the test and corresponding nodes in the advanced model have been used for the Eigen vectors are construction (total 37 nodes). When a MAC value equals to unity means $100 \%$ similarity between the vibration mode shape determined from the simulation and that obtained from the test. The MAC values for the first 4 modes detailed in the Table 3 are above 0.7 which indicates a good correlation between the modes of the advanced model and the test data. Comparison of the first 4 resonant frequencies indicate nearly low differences $(\Delta<10 \%)$. Since in the conceptual design phase in vehicle industry the focus is necessarily on low frequency range, conceptual model is able to successfully predict low frequency range. Thus, comparison of conceptual model and results is only carried out in low frequencies (less than $100 \mathrm{~Hz}$ ). The MAC criterion reduction by increment of frequency is caused by the advent of local and mixed modes reducing the accuracy of modeling prediction. Also, the generated noise during experiment and measuring uncertainties are another source of discrepancy for MAC criterion. The results of the first and forth modes were approximately precise corresponding to torsion of front rail structure and whole torsion of structure. After this step, the results of advanced model and conceptual model were compared. These results are given in Table 3 and natural frequencies error percent is also reported. According to the results, an apparently reasonable agreement was found between the conceptual model and advanced model results (the errors in Eigen values domain lie within 4\%). the mode shapes of these models were also compared in Figure 6. It was observed that the first and fourth mode shapes are approximately the same.

Table 3. Comparison of wheelhouse resonant frequencies between experiment and simulation in different mode numbers.

\begin{tabular}{llll}
\hline Mode number & Conceptual model $(\mathrm{Hz})$ & Advanced model $(\mathrm{Hz})$ & Error $(\Delta \%)$ \\
\hline 1 & 23.6 & 24 & 1.6 \\
2 & 42.4 & 42.2 & 0.5 \\
3 & 55.4 & 53.5 & 3.5 \\
4 & 75 & 73.1 & 2.6 \\
\hline
\end{tabular}



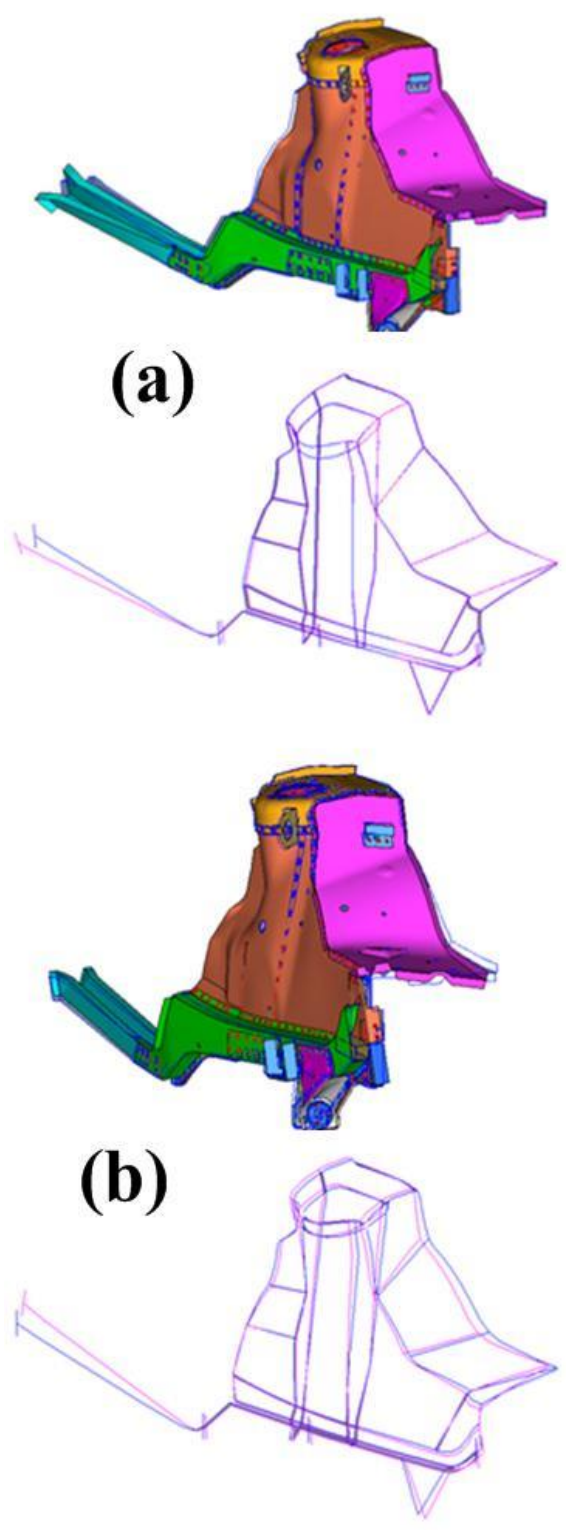

Figure 6. Wheelhouse structural dynamics: (a) first and (b) fourth mode shapes of advanced and conceptual models.

\section{Wheelhouse Structure Optimization}

The application of conceptual modeling in improving dynamic performance of structure is outlined in this section. With a reliable conceptual model, vibration performance prediction caused by possible changes can be improved. In fact, the main issue in predicting dynamic behavior of the structure is the capability of conventional methods once small changes are made in initial design. This prediction is too expensive and time consuming with traditional experimental tests and CAE analysis. For this reason, firstly sensitivity analysis is applied for the modification of first mode shape [45]. For this purpose, the most critical parameters were identified and the optimization procedure was carried out based on those parameters. Then, with the result of such analysis, optimization was applied with GA for maximizing the first natural frequency. The results of sensitivity analysis for more effective component involving in the first shape mode are given in Table 4. Also the beam parts of the structure are shown in Figure 7 with numbers from 1 to 16. 


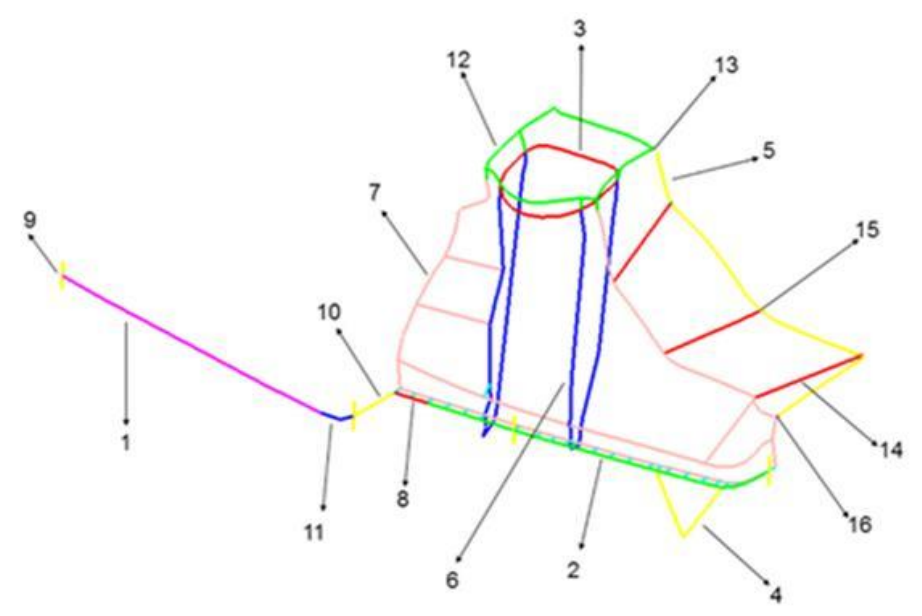

Figure 7. Beam elements of wheelhouse.

Table 4. Results of sensitivity analysis for some component of wheelhouse structure which has major role in the first mode shape of structure.

\begin{tabular}{llll}
\hline \multirow{2}{*}{ Comp. No } & \multicolumn{3}{l}{ Results of sensitivity analysis } \\
\cline { 2 - 4 } & $\mathrm{J}$ & $\mathrm{I}_{1}$ & $\mathrm{I}_{2}$ \\
\hline 1 & $2.0725 \mathrm{E}-03$ & $3.4781 \mathrm{E}-10$ & $4.2290 \mathrm{E}-06$ \\
3 & $6.5662 \mathrm{E}-05$ & $1.8628 \mathrm{E}-04$ & $4.2565 \mathrm{E}-05$ \\
7 & $3.0402 \mathrm{E}-05$ & $1.3312 \mathrm{E}-04$ & $7.5192 \mathrm{E}-06$ \\
11 & $2.6906 \mathrm{E}-02$ & $3.9821 \mathrm{E}-10$ & $8.6153 \mathrm{E}-07$ \\
14 & $6.0323 \mathrm{E}-06$ & $1.9304 \mathrm{E}-04$ & $9.8639 \mathrm{E}-05$ \\
\hline
\end{tabular}

The results of GA are given in Table 5. As seen with the GA, the first frequency increases to $41.74 \mathrm{~Hz}$. It is clear that the parameter $\mathrm{J}$ for component 11 is more effective on the first mode shape of wheelhouse structure as compared to other components. The convergence behavior of the GA which includes the variation of the best fitness during generations has been shown in Figure 8. It is obvious that at the final generation most of the individuals have the same fitness.

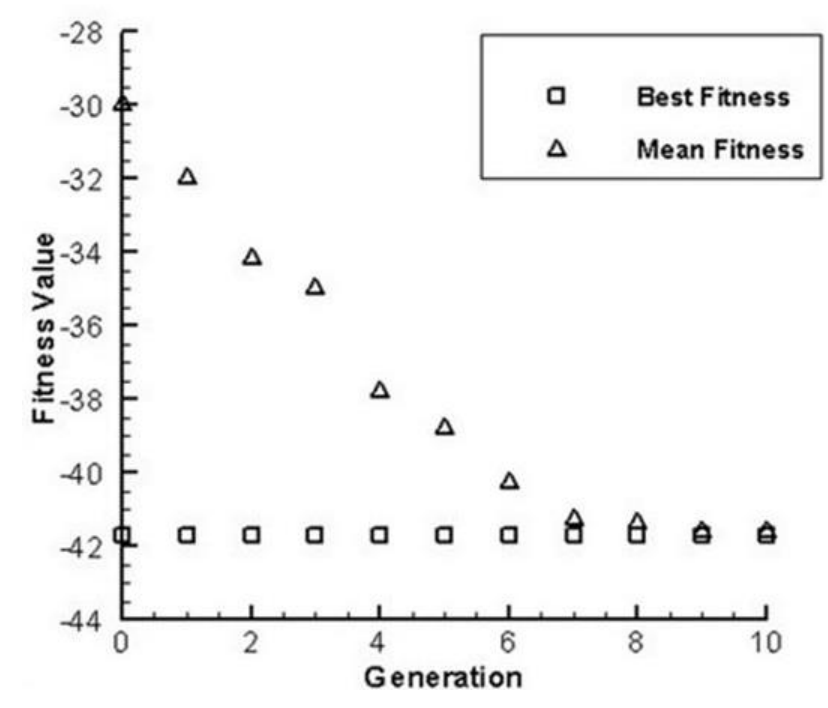

Figure 8. Convergence behavior of genetic algorithm (GA) to optimum answer. 
Table 5. Surface characteristics of the first mode shape (1) before Optimization (2) after optimization using GA.

\begin{tabular}{ccccccc}
\hline \multicolumn{7}{c}{ Surface characteristics (comp. No) $\left(\mathrm{mm}^{4}\right)$} \\
\hline & $\mathrm{J}(1)$ & $\mathrm{I}_{1}(3)$ & $\mathrm{J}(3)$ & $\mathrm{I}_{1}(7)$ & $\mathrm{J}(11)$ & $\mathrm{I}_{1}(14)$ \\
\hline$(1)$ & 104.0256 & 725.3333 & 1024 & 633.5488 & 373.1296 & 14.5833 \\
$(2)$ & 484.32580 & 1586.62245 & 1311.30030 & 690.19959 & 1920.52817 & 42.19514 \\
\hline
\end{tabular}

\section{CONCLUSIONS}

The results of wheelhouse concept model in comparison with advanced CAE and experimental model in 0-100 frequency range, revealed acceptable coincidence in terms of natural frequencies $(\Delta<10 \%)$ and MAC $(>0.75)$ for the first four mode shapes of wheelhouse structure. This method is able to make fast changes in components of conceptual model to obtain an increase in the first natural frequency, which in this case, increases to $41.74 \mathrm{~Hz}$ using GA. Due to the accuracy and reliability of developed conceptual model, this modelling approach can be a crucial tool in CAE and vibration analysis of vehicle in the early design phase. The proposed method allows the designer to give the results of design changes very quickly by neglecting details. Therefore, for the analysis of the vehicle performance in $\mathrm{NVH}$ domain, the proposed method could be considered in the conceptual design phase

\section{ACKNOWLEDGEMENTS}

This work was supported by the Noise, Acoustic and Modal Analysis Laboratory at University of Tehran.

\section{REFERENCES}

[1] Chapman CB, Pinfold M. The application of a knowledge based engineering approach to the rapid design and analysis of an automotive structure. Advances in Engineering Software. 2001;32:903-12.

[2] Kamal M, Rahman MM. Fatigue life prediction of titanium alloy for block loading using the hybrid approach of critical plane and continuum damage mechanics. International Journal of Automotive and Mechanical Engineering. 2017;14:408096.

[3] Abdullah NAZ, Sani MSM, Husain NA, Rahman MM, Zaman I. Dynamics properties of a go-kart chassis structure and its prediction improvement using model updating approach. International Journal of Automotive and Mechanical Engineering. 2017;14:3887-97.

[4] Kamal M, Rahman MM, Rahman AGA. Fatigue life evaluation of suspension knuckle using multibody simulation technique. Journal of Mechanical Engineering and Sciences. 2012;3:291-300.

[5] Bäckryd RD, Ryberg AB, Nilsson L. Multidisciplinary design optimisation methods for automotive structures. International Journal of Automotive and Mechanical Engineering. 2017;14:4050-67.

[6] Kamal M, Rahman MM. Finite element-based fatigue behaviour of springs in automobile suspension. International Journal of Automotive and Mechanical Engineering. 2014;10:1910-9. 
[7] Kamal M, Rahman MM, Sani MSM. Application of multibody simulation for fatigue life estimation. International Journal of Automotive and Mechanical Engineering. 2013;7:912-23.

[8] Fard M. Structural dynamics characterization of the vehicle seat for nvh performance analysis. SAE Paper. 2011;501:2011.

[9] Doke P, Fard M, Jazar R. Vehicle concept modeling: A new technology for structures weight reduction. Procedia Engineering. 2012;49:287-93.

[10] Moroncini A, Cremers L, Kroiss M. Nvh structural optimization using beams and shells fe concept models in the early car development phase at bmw. Proceedings of the International Conference on Noise and Vibration EngineeringISMA2010.

[11] Gur Y, Wagner D. Damping properties and nvh modal analysis results of carbon fiber composite vehicle components. SAE International Journal of Materials and Manufacturing. 2017;10:198-205.

[12] Lee S, Park J, Yim H. Numerical approximation of vehicle joint stiffness by using response surface method. International journal of automotive technology. 2002;3:117-22.

[13] Long L. Design-oriented translators for automotive joints: Virginia Polytechnic Institute and State University; 1998.

[14] Kiani M, Motoyama K, Rais-Rohani M, Shiozaki H. Joint stiffness analysis and optimization as a mechanism for improving the structural design and performance of a vehicle. Proceedings of the Institution of Mechanical Engineers, Part D: Journal of Automobile Engineering. 2014:0954407013516107.

[15] Maressa A, Mundo D, Donders S, Desmet W. A wave-based substructuring approach for concept modeling of vehicle joints. Computers \& Structures. 2011;89:2369-76.

[16] Van der Auweraer H, Van Langenhove T, Brughmans M, Bosmans I, Masri N, Donders S. Application of mesh morphing technology in the concept phase of vehicle development. International Journal of Vehicle Design. 2007;43:281-305.

[17] Mundo D, Hadjit R, Donders S, Brughmans M, Mas P, Desmet W. Simplified modelling of joints and beam-like structures for biw optimization in a concept phase of the vehicle design process. Finite Elements in Analysis and Design. 2009;45:456-62.

[18] Mundo D, Donders S, Hadjit R, Stigliano G, Mas P, Van der Auweraer H. Concept modelling of automotive beams, joints and panels. Proc World Scientific and Engineering Academy and Society (WSEAS) International Conference on FD, FEM, FV and BEM (Bucharest, Romania2010. p. 634-107.

[19] Tebby S, Barari A, Esmailzadeh E. Development of optimized preliminary vehicle structural model using simple structural beams-frames (ssb) and sub-structural analysis. Computer-Aided Design and Applications. 2014;11:544-51.

[20] Tebby S, Barari A, Esmailzadeh E. Optimization of vehicle structure considering torsion stiffness using simple structural beam frame-approach. Computer-Aided Design and Applications. 2013;10:413-26.

[21] Zhu P, Zhang Y, Chen G. Metamodel-based lightweight design of an automotive front-body structure using robust optimization. Proceedings of the Institution of Mechanical Engineers, Part D: Journal of Automobile Engineering. 2009;223:1133-47. 
[22] Shin M-K, Shin J-K, Hwang S-J, Park G-J. Structural analysis and optimization of a low-speed vehicle body. Proceedings of the Institution of Mechanical Engineers, Part D: Journal of Automobile Engineering. 2007;221:313-26.

[23] Marburg S, Hardtke H-J. Shape optimization of a vehicle hat-shelf: Improving acoustic properties for different load cases by maximizing first eigenfrequency. Computers \& Structures. 2001;79:1943-57.

[24] Liu X, Wagner J. Design of a vibration isolation actuator for automotive seating systems-part i: Modelling and passive isolator performance. International Journal of Vehicle Design. 2002;29:335-56.

[25] Liu X, Wagner J. Design of a vibration isolation actuator for automotive seating systems-part ii: Controller design and actuator performance. International Journal of Vehicle Design. 2002;29:357-75.

[26] Gündoğdu Ö. Optimal seat and suspension design for a quarter car with driver model using genetic algorithms. International Journal of Industrial Ergonomics. 2007;37:327-32.

[27] Yoshimura T, Kume A, Kurimoto M, Hino J. Construction of an active suspension system of a quarter car model using the concept of sliding mode control. Journal of Sound and Vibration. 2001;239:187-99.

[28] Hassen DB, Miladi M, Abbes MS, Baslamisli SC, Chaari F, Haddar M. Application of the operational modal analysis using the independent component analysis for a quarter car vehicle model. Advances in acoustics and vibration: Springer; 2017. p. 125-33.

[29] Wei G, Quanbo L. Simulation study on crashworthiness of car's front rail based on ls-dyna [j]. Journal of Hubei Automotive Industries Institute. 2010;2:1-7.

[30] Angelo E, Angelo G, Santos PHDG, de Andrade DA. Numerical study of the influence of elements inside the wheelhouse on the passenger vehicle aerodynamic. Open Journal of Fluid Dynamics. 2015;5:199.

[31] Lee J, Thompson D, Yoo HH, Lee JM. Vibration analysis of a vehicle body and suspension system using a substructure synthesis method. International Journal of Vehicle Design. 2000;24:360-71.

[32] Hurlebaus S, Stöbener U, Gaul L. Vibration reduction of curved panels by active modal control. Computers \& Structures. 2008;86:251-7.

[33] Sun L, Chen N, Zhao Z. Experimental modal and dynamic performances analysis of car's body-in-white. Journal of Residuals Science \& Technology. 2016;13.

[34] Lo L, Fard M, Subic A, Jazar R. Structural dynamic characterization of a vehicle seat coupled with human occupant. Journal of Sound and Vibration. 2013;332:1141-52.

[35] Zou T, Zhang J, Pang J, Li C, Liu B, Jia W, et al. The structure modal analysis and engineering application of the passenger car driver's seat system. Proceedings of SAE-China Congress 2015: Selected Papers: Springer; 2016. p. 349-63.

[36] Muller M, Weltin U, Law D, Roberts MM, Siebler TW. The effect of engine mounts on the noise and vibration behavior of vehicles. SAE Technical Paper; 1994.

[37] Nastran M. Quick reference guide. MSC SOFTWARE. 2004;1.

[38] Holland JH. Adaptation in natural and artificial systems: An introductory analysis with applications to biology, control, and artificial intelligence: U Michigan Press; 1975. 
[39] Goldberg DE. Genetic algorithms in search optimization and machine learning: Addison-wesley Reading Menlo Park; 1989.

[40] Michalewicz Z. Genetic algorithms p data structure 1/4 evolution programs, 1996. Springer: New York.

[41] Baker JE. Reducing bias and inefficiency in the selection algorithm. Proceedings of the second international conference on genetic algorithms1987. p. 14-21.

[42] Truong V-H, Nguyen P-C, Kim S-E. An efficient method for optimizing space steel frames with semi-rigid joints using practical advanced analysis and the micro-genetic algorithm. Journal of Constructional Steel Research. 2017;128:416-27.

[43] Chang Y-C, Cheng H-C, Chiu M-C, Chien Y-H. Shape optimisation of multichamber acoustical plenums using bem, neural networks, and ga method. Archives of Acoustics. 2016;41:43--53.

[44] Ewins DJ. Modal testing: Theory and practice: Research studies press Letchworth; 1995.

[45] MA Z-D, Hagiwara I. Sensitivity calculation methods for conducting modal frequency response analysis of coupled acoustic-structural systems. JSME international journal Ser 3, Vibration, control engineering, engineering for industry. 1992;35:14-21. 